\title{
QuantiFERON-TB Gold In-tube test for the diagnosis of active and latent tuberculosis in selected health facilities of Addis Ababa, Ethiopia
}

\author{
Selam Niguse ${ }^{1 *}$, Kassu Desta ${ }^{2}$, Gebremdihin Gebremichael ${ }^{3}$, Atsebeha Gebrezgeaxier ${ }^{3}$, Mulluwork Getahun ${ }^{3}$ \\ and Desta Kassa ${ }^{3}$
}

\begin{abstract}
Objective: To determine the performance of QuantiFERON-TB IN-Gold for the diagnosis active tuberculosis and latent tuberculosis.

Results: A total of 213 participants (136 tuberculosis suspects, 66 latently infected) were enrolled. Of 213, 21 (15.4\%) of the tuberculosis suspects and 3 (4.5\%) of the latent tuberculosis groups were human immunodeficiency virus infected. The sensitivity, specificity, positive and negative predictive value of QuantiFERON-TB IN-Gold for the diagnosis of active tuberculosis was 70.3\% (26/37), 49.5\% (49/99), 34.7\% (26/75) and 83.1\% (49/59) respectively. A kappa value of 0.316 ( $p=0.001,95 \% \mathrm{Cl} 1.605-1.609)$ between QuantiFERON-TB IN-Gold and tuberculin skin test were found.
\end{abstract}

Keywords: Latent tuberculosis, Active tuberculosis, QuantiFERON-TB IN-Gold, Tuberculin skin test, Human immunodeficiency virus, Addis Ababa

\section{Introduction}

Tuberculosis (TB) is still one of the deadly infectious diseases worldwide. It is estimated that around one-third of the world's population is infected with latent TB (LTBI) with $5-10 \%$ life time risk of developing active TB $[1,2]$. Presence of good diagnosis is important for the control and ultimate elimination of the disease [3]. However, diagnosis of LTBI and active TB using the existing tools is challenged by low sensitivity (in smear microscopy); need of prolonged time for results and need of sophisticated laboratories and expertise (in TB culture) [4]; relatively expensive and heterogeneous diagnostic accuracy (in molecular techniques) [5]; false positive reactions [6], lower sensitivity in immune-suppressed peoples $[6,7]$, anamnestic recall of immunity [8], potential for inter- and intra- operator variability of results [9], inconvenience for

\footnotetext{
*Correspondence: selamniguse@gmail.com

${ }^{1}$ Medical Microbiology and Immunology Department, Mekelle University, PO. Box: 1871, Mekelle, Ethiopia

Full list of author information is available at the end of the article
}

patients in tuberculin skin test, a test, based on the fact that infection with $M$. tuberculosis bacterium produces a delayed-type hypersensitivity skin reaction to certain components of the bacterium [10]. Putting all the challenges of the techniques together reinforces the need for improved diagnostic tools. Of the different tests developed, in the last 2 decades, interferon gamma release assays (IGRAs) has been introduced as an alternative test for the diagnosis of active and latent TB. There are 2 forms of IGRAs, the quantiFERON and the T-SPOT. TB. The QuantiFERON-TB Gold In-tube (QFT-GIT) uses enzyme-linked immunosorbent assay (ELISA) to measure antigen-specific production of IFN- $\gamma$ [11]. The performance of the QFT-GIT has been evaluated either for active or latent $\mathrm{TB}$, in different settings and showing a promising results. However, there is a scarcity of data from high TB and HIV burden settings. Therefore, this study is aimed at evaluating the performance of QFTGIT test for the diagnosis of pulmonary tuberculosis and 
determining the agreement of QFT-GIT test with TST in for the diagnosis of high risk populations for LTBI.

\section{Main text Methods}

A cross sectional study was carried out in Saris, Wereda 6 and Wereda 7 health centers in Addis Ababa, Ethiopia. A total of 213 study participants were consecutively enrolled from September 2012 to February 2015. Participants were adult's $\geq 18$ years and were grouped into $T B$ suspects and latent TB infection group: (1) TB suspects groups: were patients that have one or more TB specific sign and symptoms based on 2012 guidelines for clinical and programmatic management of $\mathrm{TB}$, leprosy and $\mathrm{TB} /$ HIV in Ethiopia. TB suspects visiting the health facilities during the study period and who were voluntary for HIV testing and naïve for highly active antiretroviral therapy (HAART) and anti TB treatment were recruited consecutively. TB suspects groups were tested for smear microscopy, culture and QFT-GIT. Active TB groups are diagnosed by using smear microscopy confirmed wit culture. (2) Latent TB suspects: were healthcare workers, family care givers of peoples with active TB and voluntary counseling and testing center visitors that do not have TB specific sign and symptoms. Those individuals who were voluntary for HIV testing and not recently tested for TST (with in 2 years), participants that do not have history of allergy and naïve for HAART were included. The latent groups were subjected for TST and QFT-GIT testing. Latent TB groups are identified using TST. A structured questionnaire was prepared and socio-demographic and clinical data like sex, age, and body mass index (BMI) and TB specific sign and symptoms were collected. TST testing was done using $0.1 \mathrm{ml}(2 \mathrm{TU} / 0.1 \mathrm{ml})$ tuberculin purified protein derivate (PPD) RT23 (Statens Serum Institute, Copenhagen, Denmark) were administrated intradermally with $1 \mathrm{ml}$ graduated syringe (gauge 25 or 26) in the middle third of the left forearm. The millimeters $(\mathrm{mm})$ of indurations were read within $48-72 \mathrm{~h}$. Reactions were observed and interpreted following manufacturers instruction. Sputum $(5 \mathrm{ml}$ ) (only for TB suspects) and blood $(4 \mathrm{ml})$ were collected from each participant. All the samples were transported to the national HIV and TB reference laboratory of Ethiopian Public Health Institute for laboratory analysis. Sputum samples were processed using modified Petroff's method. Sputum smears were also prepared from sediment of a processed specimen. The slides were coded, dried in air, heat fixed, and stained by Ziehl Neelsen (ZN) technique. An aliquot of $100-200 \mu$ of sputum sample was then inoculated into two tubes of Löwenstein-Jensen (LJ) medium. Identification of $M$. tuberculosis complex from other mycobacterial species was done using TB Ag MPT64 rapid capilia test
(Capilia TB-Neo, Japan). In addition to this, blood sample was added to the tube containing fluorochrome-labeled antibodies and analysed using FACS Caliber Flow cytometry analyzer for CD4 determination following the protocols of national HIV reference laboratory to determine CD4 using FACS caliber. QuantiFERON-TB In-Gold test (QFT-GIT) was performed using QFT-GIT In-tube test (Cellestis Ltd., Victoria, Australia). Briefly, $1 \mathrm{ml}$ of blood was taken in each of the three tubes precoated with TBantigen, phytohemagglutinin for the positive control or no antigen for the negative control. The cut-off point for the diagnosis was determined as per manufacturer's instruction and the test results were interpreted using software supplied by the manufacturer (Cellestis Ltd., Victoria, Australia). Data was analyzed using STATA version 10 analytical software (Statacorp LP, USA). The performance of QFT-GIT test for the diagnosis of active pulmonary TB was compared with sputum LJ culture, the gold standard test. As there is no gold standard test for latent TB, Kappa value was also calculated to see the agreement of QFT-GIT with TST.

\section{Results}

From the total, 136 were active pulmonary TB suspects and 66 were latent TB groups. All the TB suspects were screened for TB specific sign and symptoms and 132 (97.1\%) had cough of $\geq 2$ weeks and were tested by smear microscopy, culture and QFT-GIT. All the LTB groups did not have TB specific sign and symptoms (Table 1).

From 136 suspects, QFT-GIT was positive in 75 (55.1\%). Compared to the gold standard test the sensitivity, specificity, positive predictive value (PPV) and negative predictive value (NPV) of QFT-GIT for the diagnosis of active TB were 70.3\% (26/37), 49.5\% (49/99), $34.7 \%(26 / 75)$ and $83.1 \%(49 / 59)$ respectively. Thirty-two patients were positive by QFT-GIT and ZN microscopy, of which 21 were smear negatives but QFT-GIT positives, five were positive by both QFT-GIT and ZN and six patients were smear positive, but QFT-GIT negative (Table 2). However, of the culture confirmed patients, 26 (34.7\%) were smear negatives. Compared with LJ culture, the sensitivity and specificity of $\mathrm{ZN}$ microscopy in this study was 29.9 and $99 \%$, respectively. QFT-GIT were positive, negative and intermediate in 29 (50\%), 27 $(46.6 \%)$ and $2(3.4 \%)$ of the females. From adults with age 18-65 years, QFT-GIT were positive in $36(48.6 \%)$ and negative in 38 (51.4\%). In those with normal BMI (between 18.5 and $24.99 \mathrm{~kg} / \mathrm{m}^{2}$ ) QFT-GIT were positive in $36(48.6 \%)$ and negative in 38 (51.4\%). QFT-GIT results were not significantly associated with independent variables: age $\left(\mathrm{p}=0.852, \mathrm{X}^{2}=0.32\right)$, sex $(\mathrm{p}=0.182$, $\mathrm{X}^{2}=3.41$ ), Bacille Calmette Guerin (BCG) vaccination $\left(\mathrm{p}=0.638, \mathrm{X}^{2}=0.9\right)$, BMI $\left(\mathrm{p}=0.163, \mathrm{X}^{2}=6.524\right)$, 
Table 1 Characteristics of the study participants

\begin{tabular}{|c|c|c|}
\hline Category & $\begin{array}{l}\text { Tuber suspects } \\
(N=136)\end{array}$ & LTB $(\mathrm{N}=66)$ \\
\hline \multicolumn{3}{|l|}{ Sex, N (\%) } \\
\hline Female & $58(42.6)$ & 27 (50.9) \\
\hline Male & $78(57.4)$ & $26(49.1)$ \\
\hline Age, median in years (range) & $30(18-80)$ & $27(18-77)$ \\
\hline \multicolumn{3}{|l|}{ CD4 count (Cells per $\mu \mathrm{l}), \mathrm{N}(\%)$} \\
\hline$C D 4<200$ & $25(18.4)$ & $0(\%)$ \\
\hline$C D 4 \geq 200$ & $111(81.6)$ & $66(100)$ \\
\hline \multicolumn{3}{|l|}{ BMI category $\left(\mathrm{kg} / \mathrm{m}^{2}\right), \mathrm{N}(\%)$} \\
\hline $\mathrm{BMI}<18.5$ & $41(30.1)$ & $7(10.6)$ \\
\hline $18.5<\mathrm{BMl}<24.99$ & $74(54.4)$ & $43(65.2)$ \\
\hline $\mathrm{BMI} \geq 25$ & $21(15.4)$ & $16(24.2)$ \\
\hline \multicolumn{3}{|l|}{ BCG, N (\%) } \\
\hline Vaccinated & $40(29.4)$ & $42(63.6)$ \\
\hline Not vaccinated & $96(70.6)$ & $24(36.6)$ \\
\hline \multicolumn{3}{|l|}{ HIV status } \\
\hline Positive & $21(15.4)$ & $3(4.5)$ \\
\hline Negative & $115(84.6)$ & $63(95.5)$ \\
\hline \multicolumn{3}{|l|}{ Smear status, N (\%) } \\
\hline Positive & $12(8.8 \%)$ & $N A^{a}$ \\
\hline Negative & $124(91.2 \%)$ & NA \\
\hline \multicolumn{3}{|l|}{ Culture, N (\%) } \\
\hline Positive & $37(27.2)$ & NA \\
\hline Negative & $99(72.8)$ & NA \\
\hline Blood with sputum, N (\%) & $28(20.6)$ & NA \\
\hline Breath shortness, N (\%) & $90(66.2)$ & NA \\
\hline Night sweats, N (\%) & $99(72.8)$ & NA \\
\hline Chest pain, N (\%) & $110(80.9)$ & NA \\
\hline Loss of weight, N (\%) & $91(66.9)$ & NA \\
\hline
\end{tabular}

${ }^{a}$ Not applicable for testing latent tuberculosis group

smear status $\left(\mathrm{p}=0.521, \mathrm{X}^{2}=1.305\right)$, duration of cough $\left(\mathrm{p}=0.502, \mathrm{X}^{2}=5.328\right)$, sputum with $\operatorname{blood}(\mathrm{p}=0.276$, $\left.X^{2}=2.578\right)$, breath shortness $\left(p=0.852, X^{2}=3.41\right)$, night sweats $\left(\mathrm{p}=0.602, \mathrm{X}^{2}=1.013\right)$, chest pain $(\mathrm{p}=0.222$, $\left.X^{2}=3.0\right)$, and weight loss $\left(p=0.79, X^{2}=1.094\right)$. In the HIV co infected group, QFT-GIT was positive in nine. All the nine QFT-GIT positive HIV infected peoples were smear negative. From the QFT-GIT positives, five were confirmed positive by LJ culture, but four were culture negatives. With this, the sensitivity and specificity of QFT-GIT in HIV infected individuals were 62.5 and $66.7 \%$., respectively.

From the 66 peoples with latent TB, 53 (80.3\%) were TST positives. QFT-GIT were positive, negative and intermediate in 35 (53.0\%), 29 (43.9\%) and 2 (3\%), respectively. QFT-GIT has detected two individuals that were missed by TST. However, 18 TST positive individuals were negative by QFT-GIT (Table 3). From the 42 BCG vaccinated study subjects, TST were positive in
33 (78.5\%) subjects; however QFT-GIT were positive in 15 study participants. TST results were significantly associated with history of BCG vaccination $(\mathrm{p}=0.04)$, but not QFT-GIT positivity $(\mathrm{p}=2.13)$. From individuals with BMI $\left(<18.5 \mathrm{~kg} / \mathrm{m}^{2}\right)$ TST were positive and negative in $3(42.9 \%)$ and $4(57.1 \%)$, respectively whereas QFTGIT were positive in 4 (57.1) and negative in 3 (42.9\%). TST and QFT-GIT results were concordant in 44 study subjects, both QFT-GIT and TST were positive in 33 $(50 \%)$ and both were negative in $11(16.7 \%)$. The agreement between these tests were found to be fair with kappa $=0.316(\mathrm{p}=0.001), 95 \%$ CI $(1.605-1.609)$.

\section{Discussion}

The performance of QFT-GIT in this study is lower when compared to studies done in low burden developed countries [12-14]. Though findings from developing countries are heterogeneous, most of the results are similar to this study [15-18]. This was also supported with similar findings in a systemic review of studies done in low and middle income countries [19]. The difference can be explained by differences in socio-demographic and immunosuppressive diseases [20]. The sensitivity from one study done in Ethiopia was slightly lower than this study. When the cutoff value was decreased the sensitivity was improved though this affects the specificity. More studies are required to assess the discrepancy in the performance of the test in different geographical settings. In the context of HIV, the performance of QFN-GIT test was slightly decreased and relatively higher number of intermediate results was observed when compared to HIV unknown status tuberculosis patients [21]. The findings are supported by the findings from a systematic review conducted by Santin et al. [22] indicating a suboptimal sensitivity. Moreover, they also found relatively higher intermediate values in studies done in developing countries [23]. This might be due to the fact that HIV related immune-suppression affects the production of TB specific interferon gamma [24]. Moreover, the study participants are antiretroviral naïve patients in which their CD4 cells are expected to be lower than patients on treatment though the effect of antiretroviral therapy on diseasing outcome is not well known [25]. In agreement with other studies, there was no significant effect on QFT-GIT results of patients who have history of BCG vaccination. This is related with the use of highly $M$. tuberculosis-specific antigens which are not present in BCG species [26, 27].

Though cardinal diagnostic test for confirming tuberculosis suspects in developing countries is smear microscopy, we found that, the sensitivity is lower especially in HIV infected TB patients. This is due to the fact that the production of smear is compromised 
Table 2 Performance of QFT-GIT for diagnosis of active TB

\begin{tabular}{|c|c|c|c|c|}
\hline \multirow[t]{2}{*}{ Category } & \multirow[t]{2}{*}{$N^{b}$} & \multicolumn{3}{|l|}{ QFN, N (\%) } \\
\hline & & $\begin{array}{l}\text { Positive, N } \\
(\%)\end{array}$ & $\begin{array}{l}\text { Negative, N } \\
(\%)\end{array}$ & $\begin{array}{l}\text { Intermediate, } \\
\text { N (\%) }\end{array}$ \\
\hline HIV positive & 21 & $9(42.9)$ & $11(52.4)$ & $1(4.8)$ \\
\hline HIV negative & 115 & $66(57.4)$ & $48(41.7)$ & $1(0.9)$ \\
\hline $\begin{array}{l}\text { CD4 < } 200 \text { cells/ } \\
\mu \mathrm{l}\end{array}$ & 25 & $11(44.0)$ & $13(52.0)$ & $1(4)$ \\
\hline $\begin{array}{l}\text { CD4 } \geq 200 \text { cells/ } \\
\mu l\end{array}$ & 112 & $65(58.0)$ & $46(41.1)$ & $1(0.9)$ \\
\hline Smear positive & 12 & $5(41.7)$ & $7(58.3)$ & $-^{\mathrm{a}}$ \\
\hline Smear negative & 124 & $70(56.5)$ & $52(41.9)$ & $2(1.6)$ \\
\hline Culture positive & 37 & $26(70.3)$ & $10(27.0)$ & $1(2.7)$ \\
\hline Culture negative & 99 & 49 (49.5) & 49 (49.5) & $1(1.0)$ \\
\hline BCG vaccinated & 40 & $23(57.5)$ & $17(42.5)$ & $-^{\mathrm{a}}$ \\
\hline $\begin{array}{l}\text { BCG not vac- } \\
\text { cinated }\end{array}$ & 96 & $52(54.2)$ & $42(43.8)$ & $2(2.0)$ \\
\hline $\begin{array}{l}\text { Sputum with } \\
\text { blood }\end{array}$ & 28 & $19(67.9)$ & $9(32.1)$ & $-^{a}$ \\
\hline Breath shortness & 90 & $52(57.8)$ & $38(42.2)$ & $-^{a}$ \\
\hline Night sweats & 99 & $53(53.5)$ & $44(44.4)$ & $2(2.1)$ \\
\hline Chest pain & 110 & $64(58.2)$ & $45(40.9)$ & $1(0.9)$ \\
\hline Weight loss & 91 & 49 (53.8) & $40(44.0)$ & $2(2.2)$ \\
\hline
\end{tabular}

a Intermediate results were not found

b In all the percentage calculations, $\mathrm{N}$ was taken as denominator

Table 3 Concordance of QFT-GIT with
for the diagnosis latent TB

\begin{tabular}{lc}
\hline Tests combined $^{\mathbf{a}}$ & Concordance, $\mathbf{N}(\%)$ \\
\hline QFT-GIT $^{+} \mathrm{TST}^{+}$ & $33(50)$ \\
$\mathrm{QFT}^{+} \mathrm{GIT}^{+} \mathrm{TST}^{-}$ & $2(3)$ \\
$\mathrm{QFT}^{-} \mathrm{GIT}^{-} \mathrm{TST}^{+}$ & $18(27.3)$ \\
$\mathrm{QFT}^{-} \mathrm{GIT}^{-} \mathrm{TST}^{-}$ & $11(16.7)$ \\
\hline
\end{tabular}

a + positive, - negative

in patients with HIV infection [28, 29]. However QFTGIT test were shown to detect significantly many smear negatives but culture positive patients, might help increasing the case detection rate of smear negative patients. This is more important in tuberculosis suspected HIV infected individuals, as majority of the smear negatives were HIV infected with lower CD4 counts. Though HIV-associated immune-suppression, measured by circulating $\mathrm{CD}_{4}^{+}$T-lymphocytes, negatively affects the performance of QFT-GIT, its ability to identify smear negative patients could be used as a support for microbiological tests. As peoples with LTBI serve as potential reservoirs for future infections, identifying latently infected peoples using effective tests is important. In this study higher number of positive results with TST compared to QFT-GIT was observed. However The TST results were significantly affected by BCG vaccination, as majority of the BCG vaccinated subjects were positive for TST [30]. But this was not observed in QFT-GIT tests results for the diagnosis of LTBI. The findings of this study were similar with several studies [31-33]. This signifies that QFT-GIT implementation for LTBI screening minimizing false positive or negative results [34]. The discordant results lead to a fair agreement between the two tests which is relatively lower than study done by Jang et al. but relatively good agreement compared to study done by Lee et al. [35].

In conclusion, we found relatively lower sensitivity of QFT-GIT in HIV infected than TB patients without HIV. Our data also suggested QFT-GIT test has higher sensitivity in detecting smear negative TB patients and lower specificity than AFB smear microscopy in TB patients irrespective of HIV infection. This shows the potential to use QFT alone or in combination with AFB smear for the diagnosis and or screening of active TB in smear negative patients with and without HIV infection. In addition to this, despite the significant use of QFT-GIT for diagnosis of active TB, we found fair agreement with TST for screening of LTBI. Further research on both active TB and LTBI in different groups including children and in different geographical locations of resource constrained settings is needed.

\section{Limitation}

The small sample size in latent TB groups was difficult to see the risk factors affecting the performance of the tests in our study setting.

\section{Abbreviations}

AFB: acid fast bacilli; BCG: Bacille Calmette Guerin; BMl: body mass index; HAART: highly active anti-retroviral therapy; HIV: human immunodeficiency virus; IGRA: interferon gamma release assays; LTBI: latent tuberculosis infection; LJ: Lowenstein Jensen; NPV: negative predictive value; PPV: positive predictive value; QFT-GIT: quantiferon TB gold in tube; TB: tuberculosis; TST: tuberculin skin test; ZN: Ziehl-Neelsen.

\section{Authors' contributions}

NS, DK, and KD conceived and designed the study. GA, GG, and GM carried out coordination and laboratory analysis of the study. NS and KD carried out statistical analysis. NS and KD helped to draft the manuscript. All authors read and approved the final manuscript.

\section{Author details \\ ${ }^{1}$ Medical Microbiology and Immunology Department, Mekelle University, PO. Box: 1871, Mekelle, Ethiopia. ${ }^{2}$ Department of Medical Laboratory Science, Addis Ababa University, Addis Ababa, Ethiopia. ${ }^{3}$ HIV/AIDS and TB Research Directorate, Ethiopian Public Health Institute, Addis Ababa, Ethiopia.}

\section{Acknowledgements}

We would like to thank all staff of the National HIV Reference and National TB Reference Laboratory of Ethiopian Public Health Institute. Our great appreciation also goes to healthcare workers of the health facilities involved in the data collection. Our gratitude also goes to all study participants of the study. 


\section{Competing interests}

The authors declare that they have no competing interests.

\section{Availability of data and materials}

The datasets used and/or analysed during the current study are available from the corresponding author on reasonable request.

\section{Consent for publication}

Not applicable.

\section{Ethics approval and consent to participate}

The study protocol was evaluated and approved by the departmental research and Ethics review Committee of Department of Medical Laboratory Science, College of Health Sciences, Addis Ababa University and the Science and Ethical Review Office of Ethiopian Public Health Institute. Moreover, letter of cooperation were written to Addis Ababa regional health bureau and TB program managers of the region. Prior to conducting the study, the purpose and objective of the study were described to the study participants and written informed consent was obtained from each study participant. The consent involves permission to disseminate the findings of the study through scientific workshop and publish in reputable journals.

\section{Funding}

Ethiopian Public Health Institute.

\section{Publisher's Note}

Springer Nature remains neutral with regard to jurisdictional claims in published maps and institutional affiliations.

Received: 25 December 2017 Accepted: 7 May 2018

Published online: 11 May 2018

\section{References}

1. WHO. Global tuberculosis report 2014. http://apps.who.int/iris/bitst ream/10665/137094/1/9789241564809_eng.pdf. Accessed 14 Oct 2015

2. WHO. Tuberculosis factsheet 2015. http://www.who.int/features/factf iles/tuberculosis/en/. Accessed 14 Oct 2015.

3. Lönnroth K, Castro KG, Chakaya JM, Chauhan LS, Floyd K, Glaziou P. Tuberculosis tuberculosis 1 control and elimination 2010-50: cure, care, and social development. Lancet. 2010;375:1814-29.

4. Wood R. Challenges of TB diagnosis and treatment in South Africa. South Afr J HIV Med. 2007:8(2):44-8.

5. Lange C, Mori T. Advances in the diagnosis of tuberculosis. Respirology. 2010:15:220-40.

6. Stout JE, Menzies D. Predicting tuberculosis does the IGRA tell the tale? Am J Respir Crit Care Med. 2008;177:1055-7.

7. Dheda K, Udwadia ZF, Huggett JF, Johnson MA, Rook GAW. Utility of the antigen-specific interferon- $\gamma$ assay for the management of tuberculosis. Curr Opin in Pulm Med. 2005;11:195-202.

8. Pai M, Zwerling A, Menzies D. Systematic review: T-Cell-based assays for the diagnosis of latent tuberculosis infection: an update. Ann Intern Med. 2008;149:177-84

9. Balcells ME, Pe'rez CM, Chanqueo L, Lasso M, Villanueva M, Espinoza M, et al. A comparative study of two different methods for the detection of latent tuberculosis in HIV-positive individuals in Chile. Int J Infect Dis. 2008; 12:645-52.

10. Farris AB, Branda JA. QuantiFERON-TB Gold assay for tuberculosis infection. Clin Microbiol Newsl. 2007;29(17):129-36.

11. Dosanjh DPS, Hinks TSC, Innes JA, Deeks JJ, Pasvol G, Hackforth S, et al. Improved diagnostic evaluation of suspected tuberculosis. Ann Intern Med. 2008:148:325-36.

12. Sauzullo I, Mengoni F, Lichtner M, et al. In vivo and in vitro effects of antituberculosis treatment on mycobacterial interferon-gamma T cell response. PLoS ONE. 2009;4:e5187.

13. Markova R, Todorova $Y$, Drenska R, et al. Usefulness of interferongamma release asssys in the diagnosis of tuberculosis infection in HIV-infected patients in Bulgaria. Biotechnol Biotechnol Equip. 2009;23:1103-8.

14. Harada N, Higuchi K, Yoshiyama T, et al. Comparison of the sensitivity and specificity of two whole blood interferon-gamma assays for $M$. tuberculosis infection. J Infect. 2008:56:348-53.

15. Tsiouris SJ, Coetzee D, Toro PL, et al. Sensitivity analysis and potential uses of a novel gamma interferon release assay for diagnosis of tuberculosis. J Clin Microbiol. 2006:44:2844-50.

16. Pai $M$, Joshi $R$, Bandyopadhyay $M$, et al. Sensitivity of a whole-blood interferon-gamma assay among patients with pulmonary tuberculosis and variations in T-cell responses during anti-tuberculosis treatment. Infection. 2007:35:98-103.

17. Baba K, Sornes S, Hoosen AA, et al. Evaluation of immune responses in HIV infected patients with pleural tuberculosis by the QuantiFERON TB-Gold interferon-gamma assay. BMC Infect Dis. 2008;8:35.

18. Chegou NN, Black GF, Kidd M, et al. Host markers in QuantiFERON supernatants differentiate active TB from latent TB infection: preliminary report. BMC Pulm Med. 2009;9:21.

19. Metcalfe JZ, Everett CK, Steingart KR, Cattamanchi A, Huang L. Interferon- $\gamma$ release assays for active pulmonary tuberculosis diagnosis in adults in low- and middle-income countries: systematic review and meta-analysis. JID. 2011;204:S1120-9.

20. Bao L, Li T, Diao N, Shen Y, Shao L, Zhang Y, et al. Fluctuating behavior and influential factors in the performance of the QuantiFERONTB Gold In-tube assay in the diagnosis of tuberculosis. PLoS ONE. 2015;10(8):e0103763. https://doi.org/10.1371/journal.pone.0103763.

21. Legesse M, Ameni G, Mamo G, Medhin G, Bjune G, Abebe F. Performance of QuantiFERON-TB Gold In-tube (QFTGIT) for the diagnosis of Mycobacterium tuberculosis (Mtb) infection in Afar Pastoralists, Ethiopia. BMC Infect Dis. 2010;10:354.

22. Santin M, Muñoz L, Rigau D. Interferon-y release assays for the diagnosis of tuberculosis and tuberculosis infection in HIV-infected adults: a systematic review and meta-analysis. PLoS ONE. 2012;7(3):e32482. https://doi.org/10.1371/journal.pone.0032482.

23. Geldmacher C, Zumla A, Hoelscher M. Interaction between HIV and Mycobacterium tuberculosis: HIV-1-induced CD4 T-cell depletion and the development of active tuberculosis. Curr Opin HIV AIDS. 2012;7:268-75.

24. Misgina DK. The pattern of immunologic and virologic responses to highly active antiretroviral treatment (HAART): does success bring further challenges? review article. Ethiop J Health Dev. 2011;25(1):61-70.

25. Sonnenberg P, Glynn JR, Fielding K, Murray J, Godfrey-Faussett $P$, Shearer S. How soon after infection with HIV does the risk of tuberculosis start to increase? A retrospective cohort study in South African gold miners. J Infect Dis. 2005;191:150-8.

26. Esmail $H$, Barry CE, Young DB, Wilkinson RJ. The ongoing challenge of latent tuberculosis. Philos Trans R Soc B. 2014:369:20130437. https:// doi.org/10.1098/rstb.2013.0437.

27. Santin-Cerezales M, Benitez JD. Diagnosis of tuberculosis infection using interferon gamma based assays. Enferm Infecc Microbial Clin. 2011:29(Suppl 1):26-33.

28. Lawn SD, Wood R. Tuberculosis in antiretroviral treatment services in resource-limited settings: addressing the challenges of screening and diagnosis. J Infect Dis. 2011;204(Suppl 4):S1159-67.

29. Schutz C, Meintjes G, Almajid F, Wilkinson RJ, Pozniak A. Clinical management of tuberculosis and HIV-1 co-infection. Eur Respir J. 2010;36:1460-81.

30. American Thoracic Society, Centers for Disease Control and Prevention. Targeted tuberculin testing and treatment of latent tuberculosis infection. Am J Respir Crit Care Med. 2000:161(4 pt 2):S221-47.

31. Babu K, Philips M, Subbakrishna DK. Perspectives of Quantiferon TB Gold test among Indian practitioners: a survey. J Opthalmic Inflammation Infect. 2013;3:9.

32. Abdel-Samea SA, Ismail YM, Fayed SMA, Mohammad AA. Comparative study between using QuantiFERON and tuberculin skin test in diagnosis of Mycobacterium tuberculosis infection. Egypt J Chest Dis Tuberc. 2013;62:137-43.

33. Jang JY, Park IW, Choi BW, Choi JC. The usefulness of the tuberculosis skin test and the interferon-gamma release assay in the diagnosis of latent tuberculosis infection in South Korea. Osong Public Health Res Perspect. 2014;5(S):S18-23. 
34. Shah M, DiPietro D, Greenbaum A, Ketemepi S, Martins-Evora M, et al. Programmatic impact of QuantiFERON-TB Gold In-tube implementation on latent tuberculosis diagnosis and treatment in a public health clinic. PLoS ONE. 2012;7(5):e36551. https://doi.org/10.1371/journ al.pone.0036551.
35. Lee JH, Sohn HS, Chun JH, KimH SuhCH, Lee YW, et al. Poor agreement between QuantiFERON-TB Gold test and tuberculin skin test results for the diagnosis of latent tuberculosis infection in rheumatoid arthritis patients and healthy controls. Korean J Intern Med. 2014;29:76-84.
Ready to submit your research? Choose BMC and benefit from:

- fast, convenient online submission

- thorough peer review by experienced researchers in your field

- rapid publication on acceptance

- support for research data, including large and complex data types

- gold Open Access which fosters wider collaboration and increased citations

- maximum visibility for your research: over 100M website views per year

At BMC, research is always in progress.

Learn more biomedcentral.com/submissions 